\title{
PENGARUH MODEL EVALUASI LAYANAN DASAR BERORIENTASI AKUNTABILITAS TERHADAP PENINGKATAN AKUNTABILITAS GURU BK SMP
}

\author{
Aip Badrujaman ${ }^{1)}$, Furqon $^{2)}$, Syamsu Yusuf ${ }^{3)}$, Suherman $^{4)}$ \\ ${ }^{1}$ Fakultas Ilmu Pendidikan Universitas Negeri Jakarta \\ aip_bj@yahoo.com
}

2Fakultas Ilmu Pendidikan Universitas Pendidikan Indonesia

3Fakultas Ilmu Pendidikan Universitas Pendidikan Indonesia

4Fakultas Ilmu Pendidikan Universitas Pendidikan Indonesia

\begin{abstract}
This study aims to test the effectiveness of effect evaluation model of basic services oriented towards increasing the accountability of teacher accountability BK SMPN East Jakarta in organizing basic services. The research used a quantitative approach with a true research methods experiment with design waiting-list post-test only control group design. The study was conducted in East Jakarta to take the research subject teacher BK East Jakarta SMPN determined randomly as many as 37 people, divided in 17 experimental group and 16 control group. The determination of the group members using random (random assignment). The research instrument used is the scale of accountability in the review of the principal, homeroom, as well as students. Hypothesis testing is done using a technique Anacova by controlling the variables attitude towards the evaluation of basic services. The contribution of evaluation skills and attitudes towards evaluation through correlation analysis. The results showed empirically, basic service-oriented evaluation model was not able to improve the accountability of all components of the accountability of teachers BK SMPN East Jakarta in organizing basic services. Only one component of the increased accountability that is an explanation of the basic service. Variable skills to evaluate basic services make a major contribution to the implementation of the model MELDBA, while attitudes toward the evaluation does not really give contribution on MELDBA model implementation.
\end{abstract}

Keywords: experiments, program evaluation, basic services, accountability

Abstrak: Penelitian ini bertujuan menguji efektivitas pengaruh model evaluasi layanan dasar berorientasi akuntabilitas terhadap peningkatan akuntabilitas guru BK SMPN Jakarta Timur dalam menyelenggarakan layanan dasar. Penelitian menggunakan pendekatan kuantitatif dengan metode penelitian true eksperiment dengan desain waiting-list post-test only control group design. Penelitian dilakukan Jakarta Timur dengan mengambil subjek penelitian yakni guru BK SMPN Jakarta Timur yang ditentukan secara random sebanyak 37 orang yang terbagi pada 17 kelompok eksperimen dan 16 kelompok kontrol. Penentuan anggota kelompok menggunakan random (random assignment). Instrumen penelitian yang digunakan adalah skala akuntabilitas dalam tinjauan kepala sekolah, wali kelas, serta siswa. Pengujian hipotesis dilakukan menggunakan teknik ANAKOVA dengan mengontrol variabel sikap terhadap evaluasi layanan dasar. kontribusi variabel keterampilan evaluasi dan sikap terhadap evaluasi dilakukan melalui analisis korelasi. Hasil penelitian menunjukkan secara empirik, model evaluasi layanan dasar berorientasi akuntabilitas tidak mampu meningkatkan seluruh komponen akuntabilitas guru BK SMPN Jakarta Timur dalam menyelenggarakan layanan dasar. Hanya satu komponen akuntabilitas yang meningkat yaitu penjelasan mengenai layanan dasar. Variabel keterampilan melakukan evaluasi layanan dasar memberikan kontribusi besar terhadap implementasi model MELDBA, sedangkan sikap terhadap evaluasi 
tidak terlalu memberikan konrtibusi pada implementasi model MELDBA.

Kata kunci: eksperimen, evaluasi program, layanan dasar, akuntabilitas

\section{PENDAHULUAN}

Pada usia 42 tahun ini, penyelenggaraan bimbingan dan konseling di sekolah masih diliputi berbagai permasalahan. Ketua Jurusan Bimbingan Penyuluhan IKIP Bandung pertama, Buchori (2001:14) mengemukakan bahwa tenaga guru BK belum mendapatkan tempat yang layak di kebanyakan sekolah. Pendapat Buchori sejalan dengan fenomena yang terjadi pada Sekolah Menengah Atas unggulan di Jakarta seperti SMA 70, SMA 1, SMA 14, SMA 68, serta SMA 8 yang menghapus kebijakan jam bimbingan yang dilakukan melalui tatap muka 1 jam per-minggu. Kecenderungan penghapusan jam tatap muka ini diikuti juga oleh SMA yang non unggulan seperti; SMA 39, serta SMA 105. Bahkan, penghapusan jam bimbingan terjadi juga pada jenjang SMP. Beberapa sekolah SMP Negeri di Jakarta Timur yang juga menghapus jam bimbingan adalah SMPN 158, SMPN 103 dan SMPN 252.

Fenomena penghapusan jam bimbingan di atas bertolak belakang dengan kebijakan yang terkait dengan program bimbingan (guidance curriculum). Asosiasi konselor sekolah Amerika Serikat (ASCA) menempatkan program bimbingan sebagai salah satu program bimbingan dan konseling yang memiliki peran penting dalam model bimbingan dan konseling komprehensif yang direkomendasikan pada seluruh Negara Bagian di Amerika Serikat. Demikian juga dengan Asosiasi Bimbingan dan Konseling Indonesia (ABKIN) yang menempatkan layanan dasar (guidance curriculum) sebagai salah satu layanan penting dalam program bimbingan dan konseling yang diselenggarakan di sekolah. Bahkan, pentingnya layanan dasar di sekolah diperkuat oleh Peraturan Menteri Pendidikan Nasional No 22 Tahun 2006 yang mengamanatkan adanya jam tatap muka minimal 1 jam per-minggu untuk kegiatan bimbingan. Identifikasi penyebab penghapusan jam bimbingan pada banyak sekolah di DKI Jakarta perlu dilihat secara komprehensif. Secara langsung, penghapusan jam bimbingan berhubungan dengan kebijakan kepala sekolah. Meskipun demikian, kebijakan kepala sekolah tersebut mungkin terkait dengan mutu kegiatan bimbingan dan konseling yang diselenggarakan.

Penyelenggaraan layanan dasar yang kurang bermutu memunculkan dua pertanyaan besar. Pertama, mengapa layanan dasar yang semestinya dapat membantu siswa mengembangkan potensi yang dimilikinya ternyata tidak direspon positif oleh siswa. Kedua, mengapa layanan dasar yang kurang bermutu seperti itu diselenggarakan berulangulang. Berdasarkan analisis yang dilakukan, salah satu jawaban dari pertanyaan itu adalah minimnya evaluasi yang dilakukan oleh guru BK berkenaan dengan program yang diselenggarakan.

Evaluasi program bimbingan dan konseling merupakan komponen yang masih lemah dalam penyelenggaraan program bimbingan dan konseling di Indonesia. Hal ini tampak dari minimnya guru BK/konselor sekolah yang melakukan evaluasi terhadap program bimbingan dan konseling di sekolah. Studi yang dilakukan oleh Rachmalia mengenai pelaksanaan tugas pokok guru BK di kecamatan Cempaka Putih Jakarta Pusat, menunjukkan bahwa aspek evaluasi program bimbingan dan konseling masih belum banyak dilakukan. Guru BK yang menjawab selalu melakukan evaluasi layanan untuk mengetahui seberapa sukses layanan yang diberikan sebanyak $18.75 \%$, guru BK yang menjawab sering $25 \%$, sedangkan $50 \%$ menjawab kadang-kadang, dan $6.25 \%$ menjawab pernah (Rachmalia, 2006:78). Studi lain yang memperkuat fakta bahwa pelaksanaan evaluasi BK masih rendah dilakukan oleh Muryani (2008:102) yang menemukan bahwa 
kualitas pelaksanaan evaluasi pada SMA di Kecamatan Kembangan Jakarta Barat sebesar $21.01 \%$ (pencapaian maksimum $=100 \%$ )

Pelaksanaan evaluasi program bimbingan dan konseling khususnya layanan dasar yang rendah di sekolah mengakibatkan kepercayaan stakeholder terhadap program bimbingan dan konseling menjadi rendah. Fenomena penghapusan jam bimbingan merupakan indikasi rendahnya dukungan kepala sekolah terhadap pelaksanaan program bimbingan dan konseling. Guru BK belum dapat memberikan keyakinan kepada siswanya mengenai pentingnya program BK (Pancanita, 2008; Husnah, 2002). Bahkan menurut Buchori, di beberapa sekolah, guru BK dijauhi siswanya karena dipandang sebagai "polisi sekolah. Rendahnya kepercayaan terhadap program bimbingan dan konseling juga terjadi pada guru mata pelajaran yang seringkali memiliki persepsi yang kurang baik pada guru BK dan program Bimbingan dan Konseling itu sendiri. Lebih lanjut, Buchori mencatat, tidak jarang program bimbingan dan konseling hanya merupakan komponen pelengkap di sekolah sebagai persyaratan administrasi sekolah (Buchori, 2001:14).

Kepercayaan stakeholder yang masih rendah merupakan dampak dari adanya keterbatasan pada model evaluasi program bimbingan dan konseling yang digunakan. Di Indonesia, Asosiasi Bimbingan dan Konseling Indonesia sendiri masih belum memiliki model evaluasi program yang jelas. Dalam buku rambu-rambu penyelenggaraan program $\mathrm{BK}$ dalam setting pendidikan formal, ABKIN hanya menjelaskan mengenai definisi evaluasi dan aspek evaluasi, sedangkan mengenai metode evaluasi, kriteria evaluasi, teknik pengumpulan data evaluasi, dan teknik analisis, dan pelaporan, tidak terdapat dalam buku pedoman tersebut.

Berbeda dengan kondisi Indonesia, di Amerika terdapat sejumlah ahli yang telah mengemukakan dan mengembangkan model evaluasi program bimbingan dan konseling. Trotter (1998) menjelaskan aplikasi model evaluasi CIPP pada evaluasi program bimbingan dan konseling. Gysbers \& Henderson (2006) mengemukakan tiga jenis evaluasi program BK, meliputi; personel, program, dan result evaluation. Astramovich (2007) mengembangkan bridge counseling evaluation model.

Model evaluasi program bimbingan dan konseling yang dikembangkan oleh para ahli memiliki karakteristik yang menjadi pembeda satu dengan yang lain. Perbedaan utama adalah pada aspek evaluasi. Berdasarkan aspek evaluasi, terdapat tiga (3) kategori evaluasi, meliputi; evaluasi yang hanya fokus pada aspek hasil saja (goal attainment model), evaluasi yang fokus pada aspek proses dan hasil (formative and summative model; model yang dikembangkan oleh Gysbers), serta evaluasi yang fokus pada aspek perencanaan, proses, dan hasil (CIPP model, bridge counseling evaluation model) Variasi model evaluasi program dalam bimbingan dan konseling tidak membuat evaluasi kehilangan arah. Para ahli tetap menggunakan evaluasi sebagai alat untuk meningkatkan akuntabilitas program bimbingan dan konseling yang diselenggarakan oleh konselor. Gysbers (2004) menjelaskan bahwa evaluasi merupakan komponen inti dari akuntabilitas. Astramovich (2007) mengatakan bahwa evaluasi merupakan jembatan untuk meningkatkan akuntabilitas program bimbingan dan konseling.Lebih lanjut Badrujaman (2012) mengemukakan bahwa evaluasi dan akuntabilitas seperti dua sisi dalam satu mata uang logam yang tidak dapat dipisahkan. Kegiatan evaluasi menghasilkan informasi yang dapat dijadikan dasar untuk melakukan perbaikan, pada sisi yang lain, penyampaian informasi yang dihasilkan dalam evaluasi memberikan ruang bagi stakeholder untuk mengetahui, serta memberikan feedback terhadap program bimbingan dan konseling.

Berdasarkan bagan konstelasi masalah di atas, maka terdapat beberapa masalah penelitian, meliputi;

1. Apakah terdapat pengaruh model evaluasi layanan dasar berorientasi 
akuntabilitas terhadap peningkatan akuntabilitas guru BK SMP Negeri di Jakarta Timur dalam menyelenggarakan layanan dasar (guidance curriculum)?

2. Faktor apa saja yang mempengaruhi keterlaksanaan model evaluasi berorientasi akuntabilitas dalam meningkatkan akuntabilitas guru BK SMP Negeri di Jakarta Timur dalam menyelenggarakan layanan dasar?

Layanan Dasar (Guidance Curriculum). Gysbers \& Henderson (2006: 58) mengemukakan bahwa salah satu asumsi dalam konseps program BK komprehensif adalah diperlukan sebuah materi (content) dimana semua siswa butuh untuk mempelajarinya secara sistematik, dan cara yang berurutan. Hal ini berarti konselor sekolah harus mengembangkan kurikulum, yaitu kurikulum bimbingan.

Kurikulum bimbingan sesunguhnya bukanlah ide yang baru, keberadaan kurikulum bimbingan memiliki akar sejarah yang kuat. Hal yang baru mungkin berkaitan dengan susunan, teknik-teknik dalam bimbingan dan konseling, metode, dan sumber-sumber yang sekarang tersedia. Asosiasi konselor sekolah Amerika menegaskan bahwa konsep mengenai program bimbingan dan konseling komprehensif telah diorganisasikan dan diurutkan dalam sebuah kurikulum.

Bentuk kurikulum bimbingan berisi kompetensi-kompetensi yang dipilih sesuai dengan kebutuhan siswa (sesuai dengan tingkat dan jenjang) dan kegiatan yang terstruktur, yang diselenggarakan secara sistematis melalui strategi bimbingan klasikal serta kegiatan sekolah.

Di Indonesia layanan dasar memiliki prioritas tersendiri dalam layanan bimbingan dan konseling di sekolah. Layanan dasar diselenggarakan di sekolah secara rutin. Berdasarkan SK Mendikbud dan Kepala BAKN No. 0433/P/1993 dan No. 25 Tahun 1993 pasal 5 ayat 3 menyatakan bahwa guru pembimbing harus membimbing 150 orang siswa. Menurut Juntika (2004: 20) membimbing 150 orang siswa itu setara dengan mengajar di kelas selama
18 jam pelajaran perminggu. Implikasinya di sekolah, hampir setiap Sekolah Menengah Atas memiliki alokasi waktu satu (1) jam pelajaran bimbingan setiap minggunya di setiap kelas. Bimbingan kelompok inilah yang disebut sebagai bimbingan klasikal dalam layanan dasar.

Bekerja dalam kelompok atau bekerja dengan kelompok (group work) menunjuk pada seperangkat metode dan teknik yang dirancang untuk mendampingi suatu kelompok dalam meningkatkan cara dan mutu berinteraksi sedemikian rupa, sehingga menunjang pencapaian tujuan yang ditetapkan pengembangan kepribadian masing-masing anggota yang tergabung dalam suatu kelompok. Bagi guru pembimbing di sekolah, bekerja dengan kelompok berarti merancang dan mengelola serangkaian kegiatan yang memberikan pengalaman kepada siswa berinteraksi satu sama lain dalam lingkup satu kelompok. Tujuan dari bimbingan kelompok ini adalah menunjang perkembangan pribadi, perkembangan sosial, serta perkembangan belajar dan karir siswa.

Dalam hal ini, guru BK memanfaatkan proses kelompok (group process), yaitu interaksi dan komunikasi yang berlangsung antara anggota peserta kegiatan bimbingan kelompok yang bekerjasama untuk memenuhi suatu kebutuhan yang dihayati bersama, untuk memecahkan suatu problem yang dihadapi bersama melalui tukar pikiran dalam diskusi, atau untuk merencanakan suatu aksi yang akan dilakukan bersama.

Meskipun tanggung jawab konselor sekolah termasuk juga mengorganisasikan dan mengimplementasikan kurikulum bimbingan, kerjasama dan dukungan dari pihak pimpinan sekolah dan staf sungguh penting dalam rangka kesuksesan implementasi. Orang tua dan wali juga dilibatkan untuk memberikan masukan bagi program bimbingan dan konseling terutama kurikulum bimbingan. Hal ini juga dimasudkan agar orang tua dan wali memberikan dukungan dan dorongan proses bimbingan di rumah. Bentuk pelaksanaan bimbingan kelompok secara klasikal (group guidance class) menjadi ciri khas dari model bimbingan yang ada sekarang ini. Hal ini tampak pada adanya jam bimbingan 
di sekolah Model Evaluasi Layanan Dasar Berorientasi Akuntabilitas

MELDBA memberikan fokus evaluasi pada empat (4) aspek, meliputi; perencanaan, proses, hasil, dan dampak. Aspek perencanaan merupakan aspek evaluasi ketika program masih berbentuk perencanaan. Aspek proses merupakan aspek pelaksanaan program yang ditelaah secara berkelanjutan sehingga program terlaksana secara efektif. Aspek hasil merupakan output dari program yaitu pencapaian tujuan layanan. Aspek terakhir adalah dampak, aspek ini merupakan dampak dari program bimbingan terhadap pencapaian hasil belajar siswa. MELDBA dilakukan secara berkelanjutan mulai dari evaluasi perencanaan, proses, hasil, serta dampak. Hasil evaluasi pada setiap aspek kemudian diinformasikan kepada stakeholder yang berkepentingan. Berikut disajikan alur dari MELDBA 


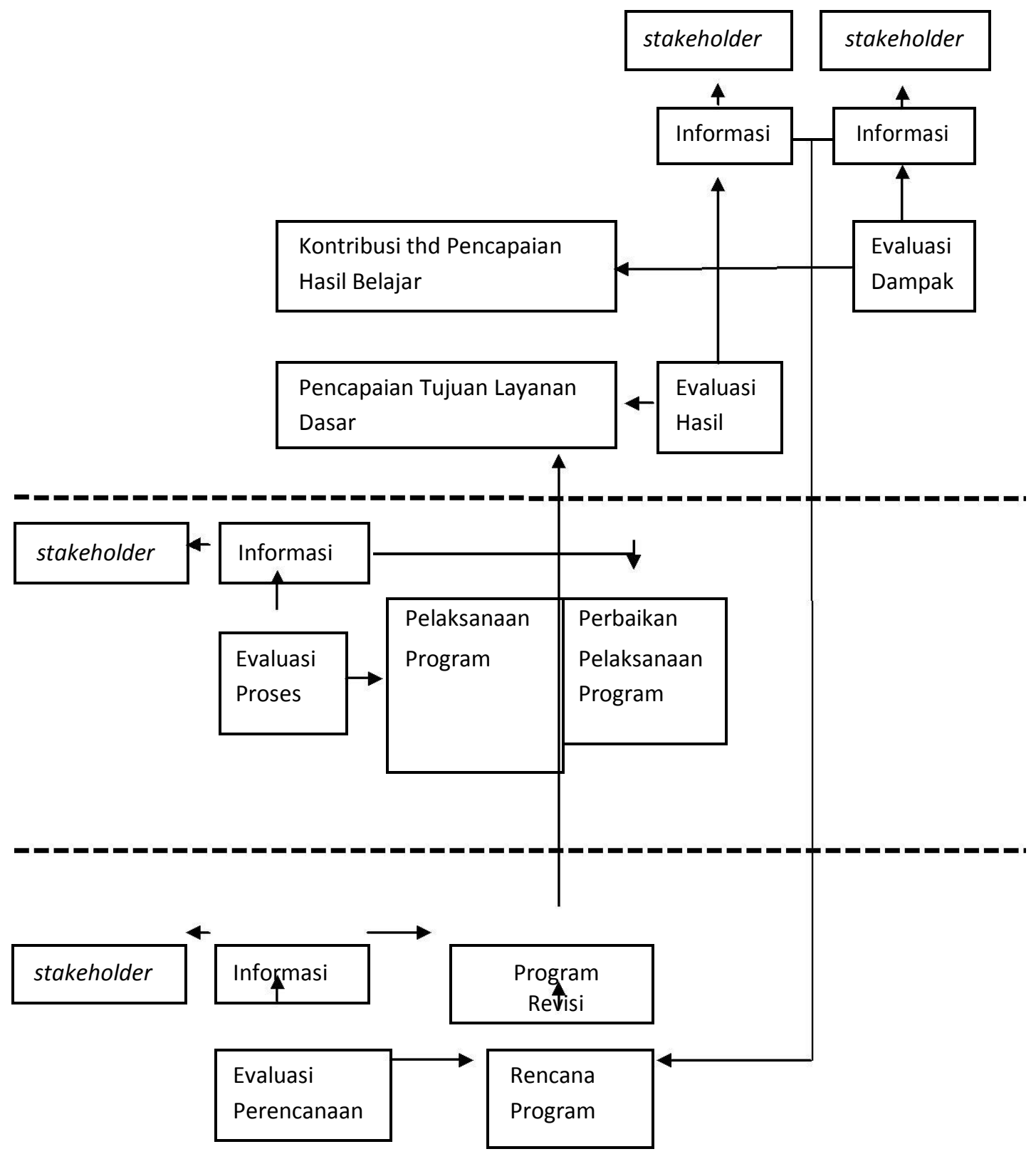

Bagan 1: Model Evaluasi Layanan Dasar Berorientasi Akuntabilitas (MELDBA) 
Berdasarkan alur evaluasi di atas, dapat diketahui bahwa evaluasi dimulai pada saat program masih menjadi rencana. Dalam konteks layanan dasar, perencanaan program dapat diketahui melalui dokumen yang disebut dengan satuan layanan atau rencana pelaksanaan pelayanan (RPP). Evaluasi perencanaan dilakukan untuk menelaah kesesuaian satuan layanan atau RPP yang telah dikembangkan dengan kebutuhan peserta didik. Hasil evaluasi perencanaan selanjutnya menjadi dasar perbaikan satuan layanan atau RPP. Pada saat yang bersamaan, hasil evaluasi perencanaan juga diberikan kepada kepala sekolah sebagai atasan guru BK. Satuan layanan atau RPP yang telah direvisi berdasarkan rekomendasi evaluasi perencanaan kemudian dilaksanakan.

Bersamaan dengan pelaksanaan layanan dasar, maka evaluasi proses dilakukan. Evaluasi proses dilakukan dalam rangka mengidentifikasi kekurangan yang ada dalam pelaksanaan, sehingga dapat segera diperbaiki. Hasil evaluasi proses juga diinformasikan kepada kepala sekolah. Pada bagian akhir program, evaluasi hasil dilakukan untuk mengetahui capaian tujuantujuan layanan dasar. Hasil dari evaluasi hasil kemudian diinformasikan kepada stakeholder, baik kepala sekolah, wali kelas, serta siswa. Tahap terakhir dalam evaluasi MELDBA ini adalah melakukan evaluasi dampak. Evaluasi dampak dilakukan untuk mengetahui kontribusi layanan dasar terhadap pencapaian hasil belajar siswa. Hasil evaluasi hasil dan dampak kemudian dijadikan dasar untuk memperbaiki perencanaan layanan dasar.

\section{Akuntabilitas Layanan Dasar}

Akuntabilitas merupakan konsep penting dalam penyelenggaraan program bimbinan dan konseling . akuntabilitas sekarang telah menjadi tuntutan dan kebutuhan yang tidak dapat dihindarkan dari pelaksanaan program bimbingan dan konseling. Myrick (2003) menyebutnya sebagai suatu tuntutan. Asosiasi konselor sekolah Amerika (ASCA) bahkan memasukkan akuntabilitas sebagai salah satu dari empat komponen dalam program bimbingan dan konseling komprehensif, selain delivery sistem, dan philosophy.

Akuntabilitas (accountability) merupakan istilah yang digunakan oleh banyak diSsiplin ilmu, terutama yang berkaitan dengan pelayanan publik. Oleh karena itu, konsep akuntabilitas pada BK tidak lepas dari pengaruh konsep akuntabilitas pada bidang administrasi. Untuk memperkaya dan mendapatkan pemahaman yang utuh, penulis sengaja mengkaji pengertian akuntabilitas dalam perspektif administrasi, dan perspektif BK.

Akuntabilitas program BK mulai menjadi pembahasan yang intensif karena disebabkan oleh faktor internal dan faktor eksternal. Faktor internal yang mendorong pembahasan mengenai akuntabilitas adalah adanya kesadaran dan perkembangan profesi BK. Sebagai sebuah profesi, BK menyadari bahwa profesionalisme adalah cara agar masyarakat memiliki kepercayaan dalam menggunakan jasa profesi BK. Kondisi ini sejalan dengan adanya reformasi pendidikan di banyak Negara termasuk Indonesia. Anggaran pendidikan yang terbatas membuat pengelola program BK mampu mempertanggungjawabkan anggaran yang diperoleh.

Dalam penyelenggaraan program bimbingan dan konseling, istilah akuntabilitas banyak digunakan oleh ahli maupun praktisi bimbingan dan konseling secara pararel dengan program bimbingan dan konseling. terkadang, istilah akuntabilitas yang digunakan tersebut merujuk pada rujukan (reference) yang berbeda. Pertama, istilah akuntabilitas seringkali digunakan untuk 
menggantikan kata evaluasi (Gysbers,2003; Stone dan Dahir, 2009; Dimmitt, 2009). Sementara, ahli yang lain, berpendapat akuntabilitas tidak sama dengan evaluasi. Evaluasi merupakan factor yang mempengaruhi akuntabilitas (Myrick, 2003; Astramovich, 2007; Sink, 2009)

Akuntabilitas merupakan suatu keadaan yang tidak bersifat dikotomis. Bahkan, akuntabilitas merupakan keadaan yang bersifat dinamis, yang memiliki rentangan secara kontinum. Tinggi atau rendah, naik atau turunnya keadaan tersebut tentunya sangat dipengaruhi oleh komponenkomponen yang ada dalam konsep akuntabilitas tersebut. Komponen dalam akuntabilitas dengan sendirinya dapat dipandang sebagai indicator-indikator yang menjadi dasar ukuran akuntabilitas itu sendiri. Berdasarkan kajian literatur mengenai konstruk akuntabilitas yang dikemukakan para ahli, peneliti mendefinisikan akuntabilitas sebagai suatu keadaan dimana guru bimbingan dan konseling mampu menerima tanggungjawab, melakukan komunikasi, menjelaskan, menetapkan mekanisme umpan balik, serta melakukan perbaikan program bagi stakeholder.

\section{METODOLOGI PENELITIAN}

Penelitian pengaruh model evaluasi layanan dasar berorientasi akuntabilitas terhadap peningkatan akuntabilitas guru BK SMPN Jakarta Timur dalam menyelenggarakan layanan dasar menggunakan pendekatan kuantitatif. Pendekatan kuantitatif adalah pendekatan yang berupaya menjawab pertanyaan yang spesifik, mengumpulkan data yang berbentuk angka, menggunakan statistik dalam analisis data, serta melakukan studi yang tidak bias dan objektif (Creswell, 2008:46). Pendekatan kuantitatif dipilih karena kajian konseptual mengenai model evaluasi program bimbingan dan konseling sudah cukup banyak dan lama. Oleh karena itu yang diperlukan adalah menguji teori pada situasi yang khusus (justifying), yang menjadi orientasi pendekatan kuantitatif (Heppner et al, 2008; Gall et al., 2007)

Metode penelitian eksperimen dipilih untuk mengetahui pengaruh model evaluasi layanan dasar berorientasi akuntabilitas terhadap peningkatan akuntabilitas layanan dasar. Metode eksperimen merupakan metode penelitian yang berusaha menjawab pertanyaan bagaimana (how question). Pada penelitian eksperimen, pengujian jawaban dilakukan melalui suatu percobaan yang melibatkan perlakuan untuk mengetahui pengaruh suatu variabel bebas (treatment variabel) terhadap suatu variabel terikat (dependent variabel). Creswell meongungkapkan bahwa penelitian eksperimental bertujuan explaining whether an an intervention influences an outcome for one group as opposed to another group (Creswell, 2008: 299). Oleh karena itu, pada hakikatnya, metode eksperimen tidak hanya menyediakan jawaban mengenai pengaruh suatu variabel terhadap variabel yang lain, akan tetapi juga menghasilkan suatu produk yang dapat digunakan dalam setting yang lebih praktis.

Penelitian pengaruh model evaluasi layanan dasar berorientasi akuntabilitas terhadap peningkatan akuntabilitas guru BK SMPN Jakarta Timur dalam menyelenggarakan layanan dasar (guidance curriculum) dilakukan di wilayah Kota Jakarta Timur. Lokasi ini dipilih berdasarkan studi pendahuluan dan kajian hasil penelitian terdahulu yang menunjukkan bahwa terdapat masalah penghapusan jam bimbingan. Populasi penelitian pengaruh model evaluasi layanan dasar berorientasi akuntabilitas terhadap akuntabilitas layanan dasar (guidance curriculum) adalah guru SMP Negeri di Jakarta Timur yang 
menyelenggarakan layanan dasar berjumlah 209 orang guru BK.

Terdapat dua kali pengambilan sampel yang dilakukan dalam penelitian ini. Pertama adalah pada saat peneliti menentukan jumlah dan siapa saja sampel dalam penelitian. Kegiatan pemilihan sampel dilakukan melalui simple random sampling, oleh karena itu kegiatan ini disebut juga sebagai random selection (Hepner et al, 2008; furqon, 2011). simple random sampling dipilih agar peneliti dapat melakukan generalisasi secara meyakinkan karena sampel benar-benar mewakili populasinya. Berdasarkan hasil undian, maka diperoleh 54 guru BK Sekolah Menengah Pertama Negeri di Jakarta Timur (25\% dari populasi) menjadi sampel dalam penelitian.

Teknik sampling kedua yang dilakukan dalam penelitian ini dilakukan untuk membagi sampel dalam kelompok eksperimen dan kontrol (random assignment) yang juga dilakukan menggunakan simple random sampling. Teknik ini dipilih agar kedua kelompok (eksperimen dan kontrol) dapat relatif setara sehingga berbagai perbedaan individu tidak menjadi penyebab bias dan menurunkan validitas internal penelitian. Berdasarkan undian, terpilih 27 orang guru BK yang menjadi kelompok eksperimen dan 27 guru BK yang menjadi kelompok kontrol.

Bentuk kelompok kontrol yang dipilih dalam penelitian adalah waiting-list Control group. Bentuk kelompok kontrol ini dipilih sebagai bentuk perhatian terhadap aspek etis dalam penelitian. Pada bentuk waiting-list, treatment dilakukan menunggu hasil treatment pada kelompok eksperimen. Pengukuran terhadap akuntabilitas pada kelompok kontrol dilakukan diakhir semester yaitu bulan Januari 2013. Pada proses pengukuran, didapati 7 sekolah yang tidak memberikan izin dilakukan penelitian, dan 4 data akuntabilitas guru BK yang tidak lengkap. Oleh karena itu, terjadi juga perubahan jumlah sampel pada kelompok kontrol, yaitu menjadi 16 Berikut disajikan sampel akhir baik pada kelompok eksperimen dan kontrol

Penelitian ini bertujuan untuk mengetahui pengaruh model evaluasi layanan dasar berorientasi akuntabilitas terhadap peningkatan akuntabilitas layanan dasar guru SMP Negeri di Jakarta Timur. Oleh karena itu, instrumen penelitian yang digunakan untuk mengukur variabel terikat adalah instrumen akuntabilitas layanan dasar yang memiliki reliabilitas sangat tinggi, meliputi; instrument akuntabilitas kepala sekolah $(0,96)$, wali kelas $(0,91)$, serta siswa $(0,83)$. Instrument sikap terhadap evaluasi memiliki reliabilitas 0,92 , sedangkan instrument keterampilan evaluasi layanan dasar memiliki reliabilitas 0,44.

Untuk menguji pengaruh model evaluasi berorientasi akuntabilitas terhadap komponen akuntabilitas layanan dasar pada guru smpn jakarta timur dilakukan dengan mempertimbangkan variabel sikap terhadap evaluasi sebagai variabel kovariat. Analisis menggunakan teknik analisis kovarians (ANAKOVA). ANAKOVA merupakan teknik gabungan dari analisis varians dan regresi. Oleh karena itu, statistic yang digunakan dalam pengujian hipotesis adalah uji $\mathrm{F}$ untuk membandingkan perbedaan skor akuntabilitas pada kelompok eksperimen dan kontrol pada saat variabel sikap dikontrol. Selanjutnya, pengaruh model evaluasi layanan dasar berorientasi akuntantabilitas ditafsirkan dari tingkat signifikansi yang diperoleh pada setiap nilai F. Oleh karena itu, H0 ditolak jika F hitung yang diperoleh menunjukkan signifikansi $\rho$ $<\alpha=0,05$. 


\section{HASIL DAN PEMBAHASAN}

Hasil pengujian hipotesis mengenai pengaruh model evaluasi berorientasi akuntabilitas terhadap akuntabilitas layanan dasar menunjukkan $\mathrm{F}=0,186$ dengan tingkat kepercayaan $\rho=0,669>\alpha=0,05$. Hasil Pengujian tersebut menunjukkan Ho diterima, berarti tidak terdapat pengaruh model evaluasi berorientasi akuntabilitas terhadap peningkatan akuntabilitas layanan dasar.

Pengaruh model evaluasi MELDBA terhadap peningkatan akuntabilitas juga dilakukan secara rinci pada masing-masing komponen akuntabilitas. Pengaruh model MELDBA pada komponen menerima tanggungjawab layanan dasar menunjukkan $\mathrm{F}=1,321$ dengan tingkat kepercayaan $\rho=0,259>\alpha=0,05$. Hasil Pengujian tersebut menunjukkan Ho diterima, berarti tidak terdapat pengaruh model evaluasi berorientasi akuntabilitas terhadap komponen peningkatan penerimaan tanggungjawab layanan dasar. Pengujian pengaruh model MELDBA pada komponen melakukan komunikasi dengan stakeholder layanan dasar menunjukkan $\mathrm{F}=1,226$ dengan tingkat kepercayaan $\rho=0,269>\alpha=0,05$. Hasil Pengujian tersebut menunjukkan Ho diterima, berarti tidak terdapat pengaruh model evaluasi berorientasi akuntabilitas terhadap peningkatan komunikasi dengan stakeholder. Pengaruh model evaluasi berorientasi akuntabilitas terhadap komponen menjelaskan layanan dasar kepada stakeholder menunjukkan $\mathrm{F}=10,613$ dengan tingkat kepercayaan $\rho=0,003<\alpha=0,05$ Hasil Pengujian tersebut menunjukkan Ho ditolak, berarti tidak terdapat pengaruh model evaluasi berorientasi akuntabilitas terhadap peningkatan penjelasan layanan dasar kepada stakeholder. Hasil pengolahan tehadap uji pengaruh model evaluasi berorientasi akuntabilitas terhadap komponen memiliki mekanisme umpan balik layanan dasar menunjukkan $\mathrm{F}=0,477$ dengan tingkat kepercayaan $\rho=0,495>\alpha=0,05$. Hasil Pengujian tersebut menunjukkan Ho diterima, berarti tidak terdapat pengaruh model evaluasi berorientasi akuntabilitas terhadap peningkatan kepemilikan mekanisme umpan balik layanan dasar. Hasil pengolahan tehadap uji pengaruh model evaluasi berorientasi akuntabilitas terhadap peningkatan perbaikan layanan dasar menunjukkan $\mathrm{F}=0,010$ dengan tingkat kepercayaan $\rho=0,921>\alpha=0,05$. Hasil

Pengujian tersebut menunjukkan Ho diterima, berarti tidak terdapat pengaruh model evaluasi berorientasi akuntabilitas terhadap peningkatan perbaikan layanan dasar. Analisis korelasi dilakukan berdasarkan data 33 responden. Analisis korelasi terdiri atas 2 bagian, yaitu korelasi variabel keterampilan evaluasi terhadap keterlaksanaan evaluasi, dan korelasi variabel sikap terhadap evaluasi dan keterlaksanaan evaluasi. Berdasarkan uji persyaratan analisis data, diketahui variabel keterampilan dan keterlaksanaan tidak berasal dari populasi yang berdistrubusi normal, maka uji hipotesis menggunakan statistic non-parametrik dengan rumus Kendall Tau. Berdasarkan analisis korelasi, diketahui bahwa koefisien korelasi keterampilan evaluasi dan keterlaksanaan evaluasi sebesar 0,485. Koefisien ini kemudian diuji lebih lanjut menggunakan uji T. Berdasarkan pengujian hipoetsis, diketahui nilai $\mathrm{t}=3,09$ lebih besar dari t table (pada taraf siginikansi $\alpha=0,05$ dan derajat kebebasan = 31) 1,697<3,09, maka H0 ditolak, koefisien korelasi signifikan, jadi keterampilan evaluasi berkontribusi signifikan terhadap keterlaksanaan evaluasi Berdasarkan analisis korelasi, 
diketahui bahwa koefisien korelasi keterampilan evaluasi dan keterlaksanaan evaluasi sebesar 0,485. Koefisien ini kemudian diuji lebih lanjut menggunakan uji T. Berdasarkan pengujian hipoetsis, diketahui nilai $\mathrm{t}=1,18$ lebih kecil dari $\mathrm{t}$ table (pada taraf siginikansi $\alpha=0,05$ dan derajat kebebasan $=31)=1,697>1,18$, maka $\mathrm{H} 0$ diterima, koefisien korelasi tidak signifikan , jadi sikap terhadap evaluasi tidak memberikan kontribusi signifikan terhadap keterlaksanaan evaluasi.

Berdasarkan pengujian hipotesis yang telah dilakukan, maka diketahui bahwa hipotesis nol tidak ditolak yang berarti tidak ada pengaruh model layanan dasar berorientasi akuntabilitas terhadap peningkatan akuntabilitas guru BK SMPN Jakarta Timur dalam menyelenggarakan layanan dasar. Hasil ini penelitian ini dengan sendirinya tidak mengkonfirmasi teori yang menyatakan bahwa model evaluasi layanan dasar berorientasi akuntabilitas dapat meningkatkan akuntabilitas guru BK/konselor (Astramovich;2007). Penelitian menunjukkan bahwa meskipun secara kasat mata, skor akuntabilitas kelompok eksperimen lebih tinggi dibandingkan dengan skor akuntabilitas kelompok kontrol, akan tetapi bukan disebabkan oleh model evaluasi layanan dasar, akan tetapi terjadi karena adanya error dalam penelitian, baik dalam pengambilan sampel (random error) maupun pengukuran (measurement error).

Ketidakmampuan model evaluasi layanan dasar berorientasi akuntabilitas untuk menolak hipotesis nol dipengaruhi oleh banyak faktor. Pertama dan utama adalah beban kerja guru BK. Berdasarkan SK MENPAN No 84 tahun 1993 rasio guru pembimbing dengan siswa adalah 1 berbanding 150. Rasio ini pada kenyataannya masih jauh dari harapan. Pada kelompok eksperimen, rasio guru BK dengan siswa adalah 1: 430. Bersamaan dengan itu, di sekolah, guru BK mendapatkan tugas tambahan pada kegiatan di luar wilayah kerjanya seperti guru piket, wali kelas, staf kesiswaan. Rasio yang sangat tinggi ini menjadi kontrapoduktif pada saat model evaluasi layanan dasar berorientasi akuntabilitas menuntut guru BK melakukan evaluasi pada empat aspek, yaitu perencanaan, proses, hasil, dan juga dampak.

Kegiatan evaluasi pada akhirnya membutuhkan waktu yang cukup banyak karena dilakukan mulai diawal semester, selama proses bimbingan berlangsung, serta akhir semester. Pada konteks itu, Astramovich (2004) mengungkapkan bahwa evaluasi menjadi sulit dilakukan karena membutuhkan waktu yang banyak/time counsuming. Myrick (2003) mengemukakan bahwa salah satu alasan guru BK tidak melakukan evaluasi program $\mathrm{BK}$ adalah karena tidak memiliki waktu untuk mengerjakannya. Pendapat senada juga disampaikan oleh Winkel \& Hastoeti (2006) yang mengemukakan bahwa beban kerja guru merupakan faktor penting dalam keterlaksanaan evaluasi program BK.

Beban kerja guru BK SMPN Jakarta Timur yang terlalu tinggi membuat kegiatan evaluasi yang dilakukan tidak dikuti dengan kualitas yang baik. Berdasarkan kegiatan eksperimen yang telah dilakukan, diketahui bahwa tingkat keterlaksanaan evaluasi menggunakan model MELDBA sebesar 95,8\%. Tingkat keterlaksanaan pada evaluasi hasil dan dampak lebih tinggi dibandingkan dengan tingkat keterlaksanaan evaluasi perencanaan dan proses, dimana masih terdapat 2 orang guru BK yang tidak melakukannya. Meskipun secara keseluruhan tingkat keterlaksanaan evaluasi tinggi, akan tetapi hal itu tidak diikuti dengan kualitas dari masing-masing evaluasi tersebut. Berdasarkan hasil telaah terhadap kualitas keterlaksanaan evaluasi MELDBA 
diketahui bahwa pada evaluasi proses, banyak rekomendasi dalam evaluasi yang tidak dilakukan oleh guru BK. Kondisi ini terjadi karena guru BK tidak cukup memiliki memampuan melakukan perbaikan sebagaimana yang direkomendasikan dalam evaluasi.

Temuan yang menarik adalah bahwa model evaluasi MELDBA secara signifikan menolak hipotesis nol, yang berarti bahwa terdapat pengaruh model evaluasi MELDBA terhadap peningkatan akuntabilitas guru BK SMPN Jakarta Timur dalam menyelenggarakan layanan dasar pada komponen menjelaskan layanan dasar.

Menjelaskan layanan dasar merupakan komponen penting dalam konstruk akuntabilitas. Wood Jr. \& Winston (2005: 92) mengemukakan bahwa memberikan informasi mengenai apa yang telah dilakukan kepada publik merupakan komponen penting dalam akuntabilitas. Itu berarti bahwa program harus transparans, dan memberikan akses kepada stakeholdernya untuk memperoleh informasi. Transparansi merupakan suatu proses yang dapat bersifat proaktif yang artinya informasi yang diberikan merupakan inisiasi yang datang dari pelaksana program sendiri. Transparansi yang bersifat proaktif dapat dilakukan dalam bentuk memberikan laporan terhadap kegiatan dan hasil yang telah dicapai kepada stakeholder.

Pada program bimbingan dan konseling, menjelaskan layanan dasar merupakan komponen yang sangat penting yang menjadi inti dari akuntabilitas guru $\mathrm{BK} /$ konselor itu sendiri. Ini tampak dari pendapat para ahli mengenai penjelasan akuntabilitas yang isinya berkaitan dengan data dan pemberian informasi sebagai bentuk tanggungjawab guru $\mathrm{BK} /$ konselor mengenai layanan dasar yang diselenggarakan kepada stakeholder (Stone \& Dahir,2009; White, 2007; Diltz \& Mason,
2010).

Penjelasan mengenai program (layanan dasar) merupakan komponen penting dalam akuntabilitas yang banyak dipengaruhi oleh evaluasi hasil, dan evaluasi dampak. Berdasarkan kegiatan evaluasi yang telah dilakukan selama 1 semester, diketahui bahwa seluruh guru BK dalam kelompok eksperimen (100\%) melakukan evaluasi hasil. Tingginya capaian kuantitas keterlaksanaan ini, diikuti oleh kualitas hasil evaluasi hasil. Ini tampak dari laporan evaluasi yang dibuat oleh guru BK yang secara jelas menyebutkan tingkat keberhasilan layanan dasar, baik secara keseluruhan, maupun berdasarkan tujuan layanan. Informasi ini yang kemudian diberikan oleh guru BK kepada kepala sekolah, wali kelas, serta siswa.

Kondisi yang sama juga tampak pada evaluasi dampak layanan dasar. secara kuantitas keterlaksanaan evaluasi dampak sangat tinggi, yaitu $100 \%$. Tingginya keterlaksanaan juga diikuti oleh kualitas hasil evaluasi layanan dasar yang secara tegas menyebutkan besaran kontribusi layanan dasar pada pencapaian prestasi siswa. Fenomena menarik dari evaluasi dampak adalah dari 17 guru BK SMPN Jakarta Timur yang melaksanakan evaluasi dampak, diketahui bahwa hanya terdapat 29,41\% guru BK yang mampu memberikan kontribusi nyata pada pencapaian prestasi siswa sebagai dampak penyelenggaraan layanan dasar .

Evaluasi hasil dan dampak merupakan evaluasi yang bertujuan untuk mengetahui efektifitas layanan dasar melalui pencapaian tujuan layanan dan dampaknya pada pencapaian prestasi siswa. Pemberian informasi mengenai capaian layanan dasar kepada stakeholder baik kepala sekolah, wali kelas dan siswa membuat stakeholder merasa lebih percaya terhadap guru BK dalam menyelenggarakan layanan dasar. 
Kondisi ini sejalan dengan pendapat Sink (2009) yang mengungkapkan bahwa mendemonstrasikan akuntabilitas membantu meyakinkan siswa, orangtua, guru, administrator, dan masyarakat umum akan manfaat yang terus didapat dari kualitas program BK komprehensif. Bahkan, Dahir \& Stone (2009) menekankan bahwa pengumpulan data dan pemberian informasi mengenai data kepada stakeholder merupakan kunci dari kekuatan profesi konselor.

Keterkaitan antara keterlaksanaan evaluasi hasil dan dampak dengan peningkatan akuntabilitas khususnya pada komponen penjelasan layanan dasar kepada stakeholder memunculkan dugaan bahwa dalam kondisi guru BK dengan beban kerja yang tinggi, keterampilan evaluasi yang terbatas, aspek evaluasi hasil dan dampak lebih mungkin (feasible) untuk dilaksanakan. Kata "dugaan" digunakan untuk menjelaskan level keyakinan peneliti dalam menarik kesimpulan yang mengandung kelemahan. Dugaan mengenai hubungan antara aspek evaluasi dalam model MELDBA lebih banyak disandarkan pada data penelitian yang bersifat deskriptif. Keterbatasan lain berkenaan dengan desain penelitian. Desain post-test only control group design yang digunakan tidak secara tegas memberikan informasi mengenai efektifitas dari setiap aspek evaluasi dalam model evaluasi layanan dasar berorientasi akuntabilitas. Hal ini sesuai dengan pendapat Kramer et al. (2010) yang mengungkapkan bahwa penelitian eksperimen yang menggunakan the treatment package strategy dimana dampak treatment dikaji secara keseluruhan (package) memiliki keterbatasan dalam melihat efek treatment lebih rinci. The Dismantling Strategy dapat menjadi alternatif strategi untuk mengungkap dampak model evaluasi layanan dasar berorientasi akuntabilitas pada masingmasing tipe evaluasi terhadap dimensi akutabilitas.

Implementasi evaluasi MELDBA tidak bisa dipisahkan dari manajemen sekolah khususnya manajemen bimbingan dan konseling. Model evaluasi yang komprehensif dan berorientasi akuntabilitas perlu didukung oleh manajemen yang tepat. Ini senada dengan pendapat Gabriel et al. (2013) yang menyatakan bahwa :

but change in perspective are generally not the easiest to push through. Setting up a result-based and well integrated Monitoring dan Evaluation (ME) system is not just a technical undertaking. It involves a more profound transformation of the management culture, and consequently of the attitude and behaviour of the official charge (UNESCO,2013:7).

Pendapat Gabriel et al. sejalan dengan konsep model penyelenggaraan bimbingan dan konseling komprehensif yang mengintegrasikan antara system akuntabilitas dimana evaluasi program terdapat didalamnya, dengan system manajemen yang menjadi dasar implementasi system akuntabilitas tersebut (Galassi et al., 2007; Rambu-rambu penyelenggaraan BK di Pendidikan Formal, 2007).

Implementasi evaluasi program bimbingan dan konseling khususnya layanan dasar tidak bisa terpisah dengan manajemen program BK dan manajemen sekolah Association School Counselor America (ASCA) dalam model BK Komprehensif menyebutkan bahwa sistem akuntabilitas merupakan bagian yang terkait dengan manajemen pada sisi yang lain. Sistem akuntabilitas merupakan alat manajemen 
yang berfungsi untuk menyediakan informasi sebagai dasar pengembangan program dan pertanggungjawaban kepada stakeholder.

Suherman (2011) mengungkapkan bahwa sistem manajemen adalah usahausaha melalui pemberdayaan sumberdaya yang menunjang sekolah dalam melaksanakan program bimbingan dan konseling. Manajemen merupakan pondasi yang menjadi dasar stukturisasi dan organisasi kegiatan program bimbingan dan konseling di sekolah. Lebih lanjut Suherman (2011) mengatakan bahwa keputusan dan kesepakatan manajemen dalam program bimbingan dan konseling sekolah menjamin sistem layanan bantuan untuk memenuhi kebutuhan-kebutuhan siswa lebih efektif. Untuk itu, maka perlu diperhatikan organisasi dan penugasan para konselor yang melibatkan Kepala sekolah dan administrator lainnya.

Manajemen bukan hanya variabel yang mempengauhi implementasi sistem akuntabilitas, akan tetapi manajamen juga merupakan variabel yang dipengaruhi oleh sistem akuntabilitas. Suherman (2011) mengungkapkan bahwa konselor sekolah hendaknya menggunakan hasil analisis data mengenai keefektifan keseluruhan program sebagai bahan pertimbangan dalam pengambilan keputusan manajemen berkenaan dengan perubahan isi dan pelaksanaan program bimbingan dan konseling sekolah.

Kebijakan Nasional dan sekolah yang tepat mengenai manajemen program bimbingan dan konseling merupakan suatu keniscayaan untuk menjamin efektifitas pelaksanaan evaluasi program bimbingan dan konseling sebagai sistm akuntabilitas. Sejalan dengan itu, berdasarkan penelitian yang dilakukan, Wang (2000) menemukan bahwa strategi manajemen dapat meningkatkan sistem akuntabilitas, baik manajemen dalam level mikro, maupun level makro. Artinya, implementasi sistem akuntabilitas program bimbingan dan konseling perlu didukung oleh kebijakan sekolah maupun kebijakan nasional.

Koherensi antara manajemen dan sistem akuntabilitas diperlukan dalam rangka menyelenggarakan program bimbingan dan konseling yang berkualitas. Oleh karena itu, pengkajian mengenai beban kerja guru BK, renumerisasi, dan posisi BK di sekolah menjadi faktor manajemen penting dalam mendukung implementasi sistem akuntabilitas program bimbingan dan konseling di sekolah. Goni (2007) mengungkapkan perlu adanya koherensi antara manajemen dan sistem akuntabilitas. Lebih lanjut Goni (2007) menjelaskan untuk mengembangkan sistem akuntabilitas yang baik, maka perlu dilakukan review terhadap peran dari berbagai pihak yang terlibat dalam evaluasi, meliputi; administrator, producer, innovator, dan integrator.

\section{PENUTUP}

\section{SIMPULAN}

Berdasarkan pembahasan mengenai hasil penelitian, maka dapat diidentifikasi beberapa kesimpulan penelitian, meliputi; (1) Secara umum, tidak terdapat pengaruh model layanan dasar berorientasi akuntabilitas terhadap peningkatan akuntabilitas guru BK SMPN Jakarta Timur dalam menyelenggarakan layanan dasar. akan tetapi, secara khusus model layanan dasar berorientasi akuntabilitas berpengaruh secara signifikan dalam peningkatan satu komponen akuntabilitas yaitu komponen penjelasan layanan dasar kepada stakeholder. (2) Pengaruh variabel lain terhadap akuntabilitas melalui variabel moderator yaitu keterlaksanaan evaluasi layanan dasar, adalah bahwa sikap terhadap evaluasi memberikan kontribusi secara langsung yang sangat kecil terhadap 
keterlaksanaan evaluasi (Y), sedangkan keterampilan evaluasi (X2) memberikan kontribusi yang besar terhadap keterlaksanaan evaluasi (Y).

Berdasarkan kesimpulan yang telah diambil, maka terdapat beberapa rekomendasi kepada pihak yang berkepentingan dengan hasil penelitian, yaitu;

1. Suku Dinas Pendidikan Wilayah Kota Jakarta Timur

Suku dinas pendidikan Wilayah Kota Jakarta Timur adalah institusi yang mengelola sumberdaya guru BK pada tingkat wilayah kota. Oleh karena itu, peneliti merekomendasikan kepada Suku Dinas Pendidikan Wilayah Kota Jakarta Timur agar menyelenggarakan kegiatan pelatihan untuk meningkatkan keterampilan evaluasi layanan dasar.

Rekomendasi yang kedua untuk Suku Dinas Pendidkan Wilayah Kota Jakarta Timur berkaitan dengan temuan penelitian yang menduga terdapat pengaruh beban kerja guru terhadap implementasi model evaluasi layanan dasar berorientasi akuntabilitas. Peneliti merekomendasikan Dinas Pendidikan Wilayah Kota Jakarta Timur untuk mengevaluasi efektifitas pelaksanaan program BK (termasuk evaluasi didalamnya) dengan beban kerja yang sekarang ditentukan.

\section{Guru BK SMP Negeri Jakarta Timur}

Hasil penelitian menunjukkan

keterampilan melakukan evaluasi layanan dasar guru BK SMPN Jakarta Timur rendah. Untuk itu, peneliti memberikan rekomendasi kepada guru BK SMP Negeri Jakarta Timur untuk melakukan:

a. Membuka diri dengan tuntutan akuntabilitas b. Melakukan upaya proaktif untuk meningkatkan kompetensi evaluasi

3. Peneliti Selanjutnya

Temuan penelitian menunjukkan banyak hipotesis peneliti yang teruji. Fenomena ini memunculkan serangkaian pertanyaan baru yang dapat dikaji lebih lanjut. Oleh karena itu, bagi peneliti selanjutnya, peneliti mengajukan tiga rekomendasi, sebagai berikut:

a. Pengukuran terhadap akuntabilitas perlu dilihat berdasarkan aspek evaluasi. Oleh karena itu, true experiment dengan Dismantling Strategy menjadi sebuah perbaikan yang akan memperlihatkan hasil penelitian yang lebih akurat

b. Efektifitas penggunaan model evaluasi perlu dilihat berdasarkan beban kerja guru BK dan atau manajemen BK secara komprehensif. Pelatihan peningkatan keterampilan evaluasi layanan dasar yang dikembangkan dalam penelitian belum mengukur proses, hasil, dan dampak secara ketat. Ketiadaan mengontrol variabel lain dapat menyebabkan bias dalam interpretasi terhadap adanya peningkatan keterampilan karena pelatihan. Oleh karena itu, perlu dilakukan studi lebih lanjut mengenai model pelatihan yang dapat meningkatkan keterampilan melakukan evaluasi layanan dasar

\section{DAFTAR PUSTAKA}

Alan, Green \& Susan, Keys. (2001). Meeting the Need of 21st Century Student. Professional School Counseling. Alexandria: Dec. 2001. Vol. 5, Iss. 2. 
Astramovich, Randi \& J Kelly Coker. (2007). Program Evaluation in School Counseling : The Accountability Bridge. Journal of Counseling and Development : JCD; Spring 2007; 85, 2; pg. 162

Azwar, Syaifudin. (2005). Penyusunan Skala Psikologis. Yogyakarta.

Badrujaman, Aip. (2008). Evaluasi program BK di SMA 31 Jakarta. Tesis: Universitas Negeri Jakarta (2011). Evaluasi program Bimbingan Konseling. Jakarta:Indeks.

Brinkerhoff, Robert O et al. (1986). Program Evaluation (A practitioner's Guide For Trainers and Educators. Boston: Kluwer-Nijhoff Publihing.

Brown, Duane. (2005). The ASCA National Model, Accountability, and Establishing Causal Links Between School Counselors' Activities and Student Outcome: Reply to Sink. Profesional School Counseling. Oct. vol.9, 13.

Buchori, Mochtar. (2001). Dari Guidance dan counseling ke bimbingan dan penyuluhan pendidikan. Jurnal nimbingan dan konseling vol.iv nomor 7 tahun 2001.

Costa, Daniel M et al. (2007). Preliminary report on The Accountability Scale: A Change and Outcome Measure for Intimate Partner Violonce research. Journal of violence and victim. Vol.22, 5.
Cresswell. JW. (2008). Educational research: Planning, Conducting, and Evaluating quantitative and qualitative research. 3rd Edition. Apple Sadle River, NJ: Pearson Merril Prentice Hall

Diltz, Dilani M \& Mason, Kimberly L. (2010). An Exploration of Accountability Practices of School Counselors: A National Study. Journal of Profesional counseling, Practice, Theory, and Research. Summer/Spring. Vol. 38, 52.

Dimmit, C. (2009). Why Evaluation Matters: Determining Effective School Counseling Practices. Profesional School Counseling. August. Vol. 12,6 - (2010). Evaluation in School Counseling: Current Practices and Future Possibilities. http//: cor.sagepub.com. Didownload oleh Nabila pada tanggal 3 Juli 2010.

Dahir, C. A., \& Carrolyn B Stone. (2009). School Counselor Accountability: The Path to Social Justice and Systemic Change. Journal of Counseling \& Development. Winter, vol.87, 12.

Eka, S. P. (2010). Kepuasan dan Pemanfaatan Layanan Bimbingan dan Konseling di SMP Cristoforus II.

ECB2. (2006). Panduan „Cukup Baik ${ }^{\text {ee Guna }}$ Pengukuran Dampak Dan Akuntabilitas Untuk Situasi Darurat

Fitzpatrick, J. L, et.al. (2004). Program 


\begin{tabular}{|c|c|}
\hline \multicolumn{2}{|c|}{ (Alternative } \\
\hline Approaches & and \\
\hline $\begin{array}{l}\text { Guidelines. } \\
\text { Education.. }\end{array}$ & Boston: \\
\hline
\end{tabular}

Program Evaluation (Alternative Approaches and Practical Guidelines. Boston: Pearson Education..

Goni, E. Z. (2007). Matching Publict management: accountability and evaluation in uncertain context: a practical sugestion. Journal of evaluation. Vol. 13, 4.

Gysbers, N. C. (2004). Comprehensive Guidance and Counseling Programs: The Evolution of Accountability. Profesional School Counseling. October. vol.8, 1.

Gysbers, N. C., \& Henderson, P. (2006). Developing \& Managing Your School Guidance and Counseling Program. Alexandria: American Counseling Asociation

Howieson, C., \& Sheila, S. (2000). The Evaluation of Guidance: Listening to Pupilse Views. British Journal of Guidance \& Cunseling. Cambridge. Vol. 28 (3).

Husna, S. (2002). Peranan Layanan informasi terhadap pemahaman diri siswa program percepatan belajar di smu 8. Skripsi Jurusan BK Fakultas Ilmu Pendidikan Universitas Negeri Jakarta.

Isaac, S., \& Michael, W. B. (1984). Hand Book In Reseacrh And Evaluation. California: Edits Publisher,
Isaac, M. (2003). Data-Driven Decision Making: The Engine of Accountability. Profesional School Counseling. April. Vol. 6, 228.

Jeannine, R. S., Oberman, A. H., \& Womack, R. H. (2006). Producing Evidence to Show Counseling Effectiveness in The Schools. Professional School Counseling. Alexandria. Vol 9 (5): 385-392

Jeanne, R. S., \& Oberman, A. (2006). Supervision In ASCA Models. Professional School Counseling. Alexandria. Vol 10 (1): 82-88.

Julnes, P. (2006). Performance measurement. An Effective Tool for Goverment Accountability? The Debates go on.Journal of evaluation. Vol. 12, 2.

John, J. S. (1999). Counseling in Schools. Boston: Allyn and Bacon.

Johnson, C. D., \& Johnson, S. K. (2002). Building Stronger School Counseling Programs. Greenboro: CAPS Publication.

Juntika, A dkk. (2004). Manajemen Bimbingan dan konseling. Bandung : Rosdakarya.

Lapan, R. T., \& Norman, C. G., \& Yongmin, S. (1997). The Impact of More Fully Implementated Guidance Programs on The School Experience of High School Student: A StateWide Evaluation Study. Journal of Counseling \& Development. Mar/Apr, vol.75: 292. 
Lapan, R. T. (2001). Result-Base Comprehensive Guidance and Counseling Programs: A Framework for Planning and Evaluation. Profesional School Counseling. April. vol.4 (4).

Lee, D et al. (2009). The Effect of College Counseling Service on Academic Performance and Retention. Journal of College Student Development. Vol 50 (3): 305

Levinson. (2011). Democracy, accountability, and education. Theory and research in education. Vol.9,2.

Linda, D. W., \& Brigman, G. A. (2006). Student Success Skills: Tools and Strategies for Improved Academic and Social Outcomes Professional School Counseling. Alexandria. Vol.10 (2): 112-121

Lindah. (2011). Kepuasan Siswa mengikuti Layanan Dasar di SMA 36 Jakarta. Skripsi Jurusan BK Fakultas Ilmu Pendidikan Universitas Negeri Jakarta.

Miles, M. B., \& Huberman, A. M. (1992). Analisis Data Kualitatif (Terjemahan). Jakarta: UI Press.

Myrick, R. D. (2003). Accountability: Counselors count. Professional School Counseling. Alexandria: Vol.6, Iss. 3: 174

Owen, J. (1993). Program Evaluation : Form and Approach. Sydney: Southwood Press.

Perera-Diltz, D. M., \& Mason, K. L. (2010).
An Exploration of Accountability Practices of School Counselors: A National Study. Journal of Profesional counseling, Practice, Theory, and Research. Summer/Spring. Vol. 38(52).

Poole, D. L. (2000). Evaluating performance measurement system in non-profit agencies: the program accountability quality scale (PAQS). American Journal of evaluation. Vol.21 (1)

Royse, David et al. (2006). Program Evaluation: An Introduction. Belmont: Thomson Brooks

Ryan, Katherine. (2005). Making educational accountability more democratic. American Journal of evaluation. Vol 26 (4).

Pancanita, R. I. (2008). Persepsi siswa terhadap layanan BK di SMP 92. Skripsi : Jurusan BK Fakultas Ilmu Pendidikan Universitas Negeri Jakarta.

Prayitno., \& Amti, E. (2004). Dasar-Dasar Bimbingan dan Konseling di Sekolah. Jakarta: Rineka Cipta.

Rachmalia, N. (2006). Faktor-Faktor Penghambat Pelaksanaan Tugas Pokok Guru Pembimbing. Skripsi : Jurusan BK Fakultas Ilmu Pendidikan Universitas Negeri Jakarta.

Sink et al. (2005). Comprehensive Guidance and Counseling Programs' Use of Guidance Curicula Materials: A Survey of National Trends. Jurnal Profesional School Counseling. Alexandria. Vol. 8 (4). 
Sink, C. (2007). Teacher Version of the My Class Inventory-Short Form: An Accountability Tool for Elementary School Counselors.

Profesional School Counseling. Vol 11 (2).

Sink, C. (2009). School Counselor as Accountability Leaders: Another Call for Action. Profesional School Counseling. Vol 13 (2).

Suheman, U. (2011). Manajemen Program Bimbingan dan Konseling. Bandung: Rezky Press.

Suparto, H. (1990). Diktat Kuliah Penilaian Program Bimbingan dan Konseling. Universitas Negeri Jakarta. Tidak diterbitkan.

Stapleton, Karyn and Owen Hargie. (2011). Double-Blind Accountability Dilemmas: Impression Management and Accountability Strategies Used by Senior Banking Executives. Journal of Language and Social Psychology. Vol.30

Stufflebeam, Daniel \& Antony Shienfield. (1985). Systematic Evaluation. Boston: Kluwer-Nijhoff Publihing,

Stufflebeam, Daniel. (2002). CIPP Model Ceck List.

(www.wmich.edu/evalctr/checklist).

Steenbarger, B. N., \& Smith, H. B. (1996). Assesing the Quality of Counseling Services: Developing Accountabel Helping System. Journal of Counseling \& Development. Vol 75: 145.
Teguh Arifiyadi. (2008). Konsep tentang Akuntabilitas dan Implementasinya di Indonesia. Artikel

Udin. Perbedaan Kepuasan mengikuti Layanan Dasar pada siswa yang mendapatkan dari guru yang memiliki kualifikasi S1 BK dan bukan S1 BK. Skripsi Jurusan BK Fakultas Ilmu Pendidikan Universitas Negeri Jakarta

Wang, X. (2002). Assesing Administrative Accountability: Results From National Survey. The American Review of Public Administration. Vol 32 (3).

Whiston, S. C. (1996). Accountability Through Action Research: Research Methods for Practitioners. Journal of Counseling \& Development. Vol 74: 616

White, F. A. (2007). The Professional School Counselor's Challange: Accountability. Journal of Professional Counseling, Practice, Theory, and Research. Spring. Vol 35: 62

Tim Penyusun. (2003). Pelayanan Bimbingan dan Konseling (Kurikulum Berbasis Kompetensi). Jakarta: Pusat Kurikulum, Balitbang Depdiknas.

Tim Penyusun. (2007). Rambu-rambu Penyelenggaraan BK di Pendidikan Formal. Jakarta: Dirjen PMPTK.

Timothy, A. P., Carlson, M. W., Hopper, J. A., \& Carey, J. C. (2006). Evaluation 
of an Innovative Approach to Improving Middle School Students' Academic Achievement. Professional School Counseling. Alexandria. Vol 1.9 (3): 190-197

Trotter et all. (1998). CIPP as Model Evaluation in Counseling Program. Carolina: ERIC/CASS Publications.

Trotter et all. (2004). A Survey of Assessment and Evaluation Activities of School Counselors. Professional School Counseling. Alexandria. Vol 8 (1).

Ware, W. B., \& Galassi, J. P. (2006). Using Correlational and Prediction Data to Enhance Student Achievement in K12 Schools: A Practical Application for School Counselors. Professional School Counseling. Alexandria: Vol 9 (5): 344-357.

Wood, Jr., \& Winston, B. E. (2005). Toward a New Understanding of Leader Accountability: Defining a Critical Construct. Journal of Leadership \& Organizational Studies. Vol 11 (3): 84 